\title{
FRAGMENTOS, FRACTALES Y FRONTERAS: GÉNERO Y LECTURA EN LAS SERIES DE NARRATIVA BREVE
}

LAURO ZAVALA

UAM Xochimilco, México

\begin{abstract}
El estudio de los cuentos integrados, es decir, de las series de cuentos con unidad temática, genérica o estilística, se inscribe en la discusión sobre la escritura fronteriza, ya que estas series de textos breves se encuentran a medio camino entre la novela y el cuento (en términos de extensión y estructura interna). En esa medida, su estudio ofrece una oportunidad para replantear algunos problemas fundamentales para la teoría y la crítica literaria, en particular en lo relativo a las fronteras entre escritura, edición y lectura. Además, su estudio pone en evidencia la necesidad de formular una nueva preceptiva para la teoría de los géneros literarios.

En otras palabras, el estudio de los cuentos integrados ofrece una oportunidad para replantear el eterno problema de las definiciones genéricas: ¿Qué ès un cuento? ¿Qué es una novela? Y más recientemente: ¿Qué es una minificción? ¿Cuáles son las fronteras entre estos géneros? Y más importante aún, al estudiar las series de minificción: ¿Las diferencias entre narración, ensayo y poema en prosa pueden llegar a ser producidas por el contexto de cada lectura?

En la medida en que el autor es el primer editor de los textos que escribe, podemos preguntarnos si escribir no es una estrategia para proponer modos de lectura, tanto de un mismo texto como de los textos escritos con anterioridad.
\end{abstract}

LOS CUENTOS INTEGRADOS Y OTRAS FORMAS DE ESCRITURA SERIAL

La intención central de las líneas que siguen consiste en llamar la atención sobre el hecho de que aunque en la tradición anglosajona hay ya numerosos estudios sobre los cuentos integrados, en la tradición hispano-

Rlit, LXVI, 131 (2004), 5-22 
americana no sólo existen magníficos textos que merecen ser estudiados, sino que además existe una producción literaria relacionada con la serialización y la fragmentación en la que se plantean problemas de una riqueza literaria que está ausente en otras lenguas. En particular, la riqueza de los ciclos de minificción (textos irónicos, genéricamente híbridos, cuya extensión tiende a ser menor a 400 palabras) y de las novelas constituidas exclusivamente por esta clase de textos, constituyen aportaciones literarias específicas de esta región. Aquí es necesario señalar la distinción entre distintas formas de minificción, pues este término es utilizado para hacer referencia simultáneamente a minicuentos (de carácter narrativo y estructura tradicional) y microrrelatos (de naturaleza híbrida y estructura poco convencional).

El estudio de esta preceptiva genérica y los procesos de lectura que ella exige es una múltiple asignatura pendiente. La tradición de experimentación genérica en nuestra lengua plantea problemas ligados al concepto mismo de fragmentación, proveniente de las vanguardias de principios del siglo XX.

Más aún, si se ha llegado a afirmar que la lengua franca de la novela (en su versión canónica del realismo decimonónico) fue el francés durante la segunda mitad del siglo XIX, y que la lengua franca del cuento (en su expresión canónica más tradicional) fue el inglés durante la primera mitad del siglo XX, tal vez la lengua franca de la minificción (como género proteico, ajeno a la tradición del minicuento) ha sido el español, especialmente el escrito en Hispanoamérica durante la segunda mitad del siglo XX.

Por otra parte, el estudio de los cuentos integrados y otros géneros fronterizos, fragmentarios y seriales lleva a reconocer una paulatina relativización de los cánones genéricos. Tal vez lo verdaderamente experimental hoy en día sería escribir una novela o un cuento que estuvieran exentos de fragmentación y de hibridación genérica. En ese sentido, el género que sirve como referencia obligada no es ya la novela (en su acepción más tradicional, sujeta a las reglas de verosimilitud realista) ni el cuento (en su variante clásica y epifánica, caracterizado por un final sorpresivo), sino la minificción (género literario desarrollado a lo largo del siglo $\mathrm{xX}$, que a su vez anunció el nacimiento de la escritura hipertextual).

En este trabajo señalo la existencia de varias estrategias de escritura, edición y lectura de series narrativas que permiten relativizar las fronteras convencionales entre la unidad textual (en particular, la unidad de la novela) y la diversidad genérica (en particular, la identidad de cada cuento o minificción). El estudio de los cuentos integrados y otras formas de escritura serial y fragmentaria puede llevar a la relectura y reescritura de las reglas genéricas tradicionales.

Lo que está en juego en el estudio de las series de textos breves es el reconocimiento de las posibilidades de lectura que ofrecen las manifesta- 
ciones textuales de lo mismo y lo múltiple, en la reformulación de las fronteras entre el todo y las partes. Estas estrategias son las que permiten reconocer las diferencias entre cuentos integrados, novela fragmentaria, minificciones integradas, ciclos de minificción y cuentos dispersos ${ }^{1}$.

En algunos casos todas estas formas de escritura coexisten en un mismo volumen, y el lector se enfrenta a la posibilidad de poner en juego y reformular sus estrategias de interpretación. En estos casos el texto posibilita diversas lecturas genéricas, de tal manera que un volumen puede ser leído, simultánea o alternativamente, como novela, serie de cuentos y ciclo de minificciones.

Esta simultaneidad de géneros se aleja de la ortodoxia genérica dominante a principios del siglo XX, si bien un siglo después esa ortodoxia coexiste con otras estrategias textuales. Las preceptivas más tradicionales de la novela y del cuento han dejado de lado aquello que consideran una mera anomalía o han tratado de asimilar las formas experimentales a alguno de los géneros canónicos, en lugar de reconocer el peso que tienen los contextos de interpretación que pone en juego cada lector frente a la singularidad de estos textos.

El estudio de estas formas de escritura no sólo lleva a replantear las fronteras entre géneros literarios tradicionales (por ejemplo: ¿por qué consideramos que Aura de Carlos Fuentes es una novela y que «El perseguidor» de Julio Cortázar es un cuento?), sino también a reconsiderar las estrategias de la lectura literaria. La distinción entre un género y otro no se reduce a la adopción de una preceptiva u otra, ya que hasta la fecha éstas se han limitado a establecer distinciones generales entre las formas canónicas y las formas experimentales de la novela y el cuento, y de las distinciones precisas entre narración, ensayo y poesía.

Cuando lo excepcional se convierte en la norma (o más exactamente, cuando la ruptura se convierte en una tradición de ruptura) es necesario reformular el concepto mismo de canon, y reconocer las estrategias de lectura que hacen posible la escritura de textos que sólo son excepcionales desde la perspectiva de las preceptivas originarias.

${ }^{1}$ Estas estrategias no agotan la diversidad de posibilidades de la lectura y la escritura de series de textos breves, pues las tecnologías electrónicas hacen posible que el lector participe en la creación del texto al interactuar con la pantalla, en relación con lo que aquí llamo ciclos de minificción y minificciones integradas. Los expertos en estas formas (electrónicas) de escritura literaria llaman a estos nuevos géneros simplemente hipertextos. El estudio de sus posibilidades literarias ya se ha iniciado en lengua española. Cf. Hipertexto y literatura (2000) de Jaime ALEJANDRO RODRÍGUEZ y Literatura e hipermedia $(2000)$ de Núria VoIUlLAMOZ. También pueden estudiarse algunas traducciones importantes, como Hamlet en la holocubierta (1999) de Janet H. Murria y los trabajos fundamentales de George P. Landow (Ver la bibliografía al final de este trabajo). 


\section{LA LECTURA FRAGMENTARIA COMO UN ACTO PRODUCTIVO}

El acto de leer puede tener muy diversas consecuencias en el lector. En algunos casos puede significar una suspensión momentánea de aquello que el lector sabe. Y en particular, la lectura de series textuales (incluyendo cuentos integrados) puede significar una suspensión de aquello que el lector sabe acerca de los géneros literarios.

De manera paralela al reconocimiento de este fenómeno, cada día más frecuente, sería necesario reformular la teoría tradicional de los géneros, de tal manera que en ella tengan cabida las formas de escritura (y de lectura) que surgieron y se desarrollaron durante el siglo XX. El surgimiento (durante las primeras décadas) de los textos literarios que ahora llamamos minificción es el resultado de nuevas formas de lectura y escritura literaria, y es también el anuncio de nuevas formas de leer y reescribir el mundo, pues su creación coincide con el surgimiento de una nueva sensibilidad. El reconocimiento de estas formas de escritura requiere estrategias de interpretación más flexibles que las tradicionales, es decir, estrategias que estén abiertas a incorporar las contingencias de cada contexto de interpretación.

Un primer intento de enfrentar la diversidad de formas de escritura que rebasan las preceptivas tradicionales consistió en emplear de manera recurrente y poco sistemática el término relato en oposición al término cuento (de manera similar a lo que ha ocurrido en lengua francesa con la palabra nouvelle en oposición a los términos más tradicionales, récit y conte). En lengua española, el término relato ha sido utilizado ya sea para referirse a algo más que un cuento (un cuento experimental), a algo menos que un cuento (una narración sin valor literario) o a algo diferente a un cuento (ya sea un texto híbrido, un cuento muy extenso o incluso un poema en prosa).

El surgimiento del término minificción es consecuencia directa de este nuevo contexto de lectura, donde las posibilidades de interpretación de un texto exigen reformular las preceptivas tradicionales y considerar que un género debe ser redefinido en función de los contextos de interpretación en los que cada lector pone en juego su experiencia de lectura (su memoria), sus competencias ideológicas (su visión del mundo) y sus apetitos literarios (aquellos textos con los cuales está dispuesto a comprometer su memoria y a poner en riesgo su visión del mundo).

Así, por ejemplo, a lo largo del siglo $\mathrm{xx}$ encontramos minificciones que pueden ser leídas alternativamente como poema en prosa, ensayo, crónica, alegoría o cuento, de tal manera que un mismo texto es incluido en antologías de cada uno de estos géneros. Este hecho bien conocido revela una vez más la insuficiencia de la preceptiva genérica tradicional para dar 
cabida a textos que se resisten a ser reducidos a uno $\mathrm{u}$ otro canon de lectura. Éste es el caso de las fábulas paródicas de Augusto Monterroso, las viñetas alegóricas de Juan José Arreola, las prosas irónicas de Julio Torri o los juguetes textuales de Guillermo Samperio, para sólo mencionar algunos autores canónicos del contexto mexicano contemporáneo. Por supuesto, algo similar se puede afirmar de los espantapájaros de Oliverio Girondo, los archiprólogos de Macedonio Fernández y los textos aún más inclasificables de Felisberto Hernández, para mencionar algunos autores de minificciones en el Cono Sur.

En contraste con esta riqueza literaria, en la escritura de textos muy breves en la tradición anglosajona domina la presencia de minicuentos, es decir, cuentos convencionales de tamaño reducido. Si consideramos las series de minificciones integradas como un caso extremo de cuentos integrados, es notable la casi total ausencia en lengua inglesa y en otras lenguas de genuinas minificciones (híbridas, proteicas y sometidas al rigor aleatorio de la serialización literaria), acompañada por la ausencia de una tradición del poema en prosa que haya alcanzado la diversidad y riqueza literaria que ha alcanzado en América Latina (con la notable excepción del francés).

Aquí es conveniente señalar que los textos que conforman una serie de cuentos integrados están escritos teniendo en mente su relación entre sí, de tal manera que en conjunto adquieren una clara unidad estructural. Por esta razón, algunos estudiosos han propuesto llamarlos también cuentos enlazados (Enrique Anderson Imbert) o cuentos moleculares (Slawomir Dölezel).

En términos generales, cuando la unidad entre los cuentos de un mismo libro es notable, nos encontramos ante un ciclo cuentístico (Forrest Ingram) o una secuencia cuentística (Gerald Kennedy). Esta modalidad ha sido ampliamente estudiada en la tradición anglosajona. En el estudio de Maggie Dunn \& Ann Morris (1995), que abarca más de 250 títulos, estas autoras no dudan en llamar a esta modalidad una novela compuesta, lo cual es problemático, pues puede ser conveniente distinguir entre una serie de cuentos y una novela fragmentaria ${ }^{2}$. Tan sólo en el contexto mexicano de la segunda mitad del siglo XX es posible señalar más de medio centenar de títulos que pueden caber bajo esta categoría ${ }^{3}$, mientras la tradición ge-

\footnotetext{
${ }^{2}$ Así, por ejemplo, Russell Cluff señala enfáticamente que «la secuencia cuentística, antes de formar un total coherente, es una colección de cuentos. Y no es, ni será nunca, una novela donde los apartados internos - tanto por tradición como por función práctica- sean totalmente interdependientes» (R. Cluff 1998, 66).

${ }^{3}$ La unidad temática de estas series de cuentos puede estar definida por la presencia de personajes similares que habitan un espacio común, como en El llano en llamas (1953) de Juan RULFO o en Benzulul (1959) de Eraclio ZEPEDA, y en ocasiones también por la presencia de un narrador común, como en De Zitilchén (1981) de Hernán Lara Zavala o
} 
nérica de los cuentos integrados se mantiene vigente en los escritores contemporáneos ${ }^{4}$.

La importancia de los cuentos integrados para la discusión de las fronteras entre géneros literarios es evidente. Los problemas genéricos planteados por su existencia pueden ser reconocidos también en otros ciclos narrativos. A continuación se señalan otras formas de series textuales que tienen importantes similitudes y diferencias con los cuentos integrados. En la sección final de este trabajo propongo la utilización de algunos conceptos que pueden ser útiles para el estudio sistemático de estas formas de escritura, así como para reconocer su posible articulación con otros procesos de la producción simbólica en la cultura contemporánea.

\section{LA NOVELA FRAGMENTARIA: UNA SERIE NARRATIVA NO SECUENCIAL}

Una de las estrategias más características que asume la problemática relación entre el todo y las partes en series de textos narrativos breves se encuentra en las novelas formadas por una sucesión de fragmentos cuya organización no necesariamente conserva una lógica secuencial.

El antecedente más inmediato de esta modalidad se desarrolla a lo largo del siglo XIX en forma de novela por entregas (Umberto Eco). Sin embargo, tanto en ese caso como en el de los folletines del melodrama televisivo o cinematográfico (ficcionalizados por Manuel Puig en la serie novelística iniciada en 1968 con La traición de Rita Hayworth) se conserva un orden secuencial que difícilmente se ve alterado en la estructura interna de cada capítulo.

en El ardiente verano (1954) de Mauricio MAGDALENO. La unidad genérica puede estar definida por una tradición claramente reconocible, como el cuento policiaco en La obligación de asesinar (1957) de Antonio Helú o el cuento fantástico en Una violeta de más (1968) de Francisco TARIO. Y la unidad estilística puede ser producida por un tono común a los cuentos de una serie, como la búsqueda de una verdad personal en Río subterráneo (1979) de Inés Arredondo o en El gato (1984) de Juan GARCía PONCE.

${ }^{4} \mathrm{Sin}$ salir de la narrativa mexicana podrían ser mencionados algunos ciclos de cuento en los que hay personajes que comparten espacios comunes. Ejemplos bien conocidos sobre la frontera norte son Los viernes de Lautaro (1979) de Jesús GARDEA; Registro de causantes (1992) de Daniel SADA, Tijuanenses (1989) de Federico Campbell y La frontera de cristal (1995) de Carlos FUENTES. Y en la Ciudad de México habría que señalar textos como Cerca del fuego (1975) de José Agustín y muchos otros. Entre los ciclos de cuentos policiacos o fantásticos con una notable cohesión formal pueden ser mencionados El regreso de la verdadera araña (1988) de Paco Ignacio TAIBO II o Escenas de la realidad virtual (1991) de Mauricio José SCHWARZ. Y entre los ciclos de cuento cuya unidad está determinada por el tono se podría mencionar la galería de retratos sarcásticos de la cotidianidad sentimental en Amores de segunda mano (1991) de Enrique SERNA o la combinación de erotismo, ciencia y humor en Dios sí juega a los dados (2000) de Óscar DE LA BoRBOLla. Estos títulos están elegidos un poco al azar, pero de éstos sólo el de José Agustín podría ser considerado como novela (fragmentaria). 
En cambio, cuando se habla de novela fragmentaria (Carol D'Lugo) se trata de un texto novelesco formado por fragmentos de extensión considerable, cuya separación puede estar marcada tipográficamente o por la división convencional en capítulos. Cada uno de los fragmentos puede incluir en su interior toda clase de materiales extranarrativos.

En términos estrictos se podría afirmar que toda novela es necesariamente fragmentaria. Sin embargo, la fragmentariedad que está en juego cuando se habla de novela fragmentaria consiste en la presencia simultánea de una fragmentación de la secuencia lógica y cronológica, y la presencia de elementos genéricos o temáticos en cada fragmento que garantizan la consistencia formal del proyecto narrativo.

En esta tradición literaria hay antecedentes tan prestigiosos como Al filo del agua (1947) de Agustín Yánez; La sombra del caudillo (1929) de Martín Luis Guzmán, y Los de abajo (1915) de Mariano Azuela. Y entre los textos contemporáneos más sobresalientes, sin salir del ámbito mexicano, se encuentran La región más transparente (1958), La muerte de Artemio Cruz (1962) y Cambio de piel (1967) de Carlos Fuentes; Morirás lejos (1967) de José Emilio Pacheco, y Farabeuf o la crónica de un instante (1965) de Salvador Elizondo.

En todos estos casos, el lector se ve obligado a reconstruir la secuencia de la historia narrada, al mismo tiempo que reconoce la interrelación ideológica que existe entre los acontecimientos narrados. Por esta razón, resulta paradójico el uso del término fragmento al tratar esta clase de novelas, ya que en términos estrictos cada unidad narrativa es un detalle que forma parte de una totalidad preexistente, y sin el cual no tiene sentido.

Una vez más, el peso que se otorga a la unidad total por encima de cada fragmento es consecuencia de la herencia romántica que concede todo el peso del sentido al proyecto editorial del autor. Por otra parte, la frecuencia con la que un lector decide releer, comentar o incluso memorizar alguno de estos fragmentos como una unidad autónoma confirma la tesis dominante en la actual teoría de la recepción, en la cual se reconoce que la historia de la literatura la escriben las sucesivas generaciones de lectores, precisamente al reconocer aquello que les resulta significativo en su contexto de lectura. Esto ocurre, por ejemplo, con el poético lenguaje erótico del capítulo 68 en la Rayuela (1963) de Julio Cortázar; el espléndido capítulo sobre las variantes de la palabra secreta en La muerte de Artemio Cruz (1962) de Carlos Fuentes; los barrocos monólogos del poder en Yo el Supremo (1974) de Augusto Roa Bastos, o las aventuras eróticas reconstruidas por un narrador irónico en La Habana para un Infante difunto (1980) de Guillermo Cabrera Infante.

En ese sentido, la no secuencialidad de la novela fragmentaria pone en marcha mecanismos de lectura similares a los que se ponen en juego durante la reconstrucción de la experiencia de ver una película construida a 
partir de la espacialización del tiempo, es decir, al reconstruir en orden secuencial aquello que ocurrió de manera simultánea, y al recordar aquellos fragmentos que metonímicamente sustituyen a otros de la misma serie. La lectura de textos fragmentarios (donde suele dominar la técnica del monólogo interior) pone en evidencia la fragilidad de los géneros tradicionales, pues la experiencia cotidiana es, por definición, una experiencia del fragmento. Las convenciones genéricas son puestas en evidencia precisamente cuando su ausencia es más notoria.

\section{MINIFICCIONES INTEGRADAS: LA NOVELA DE FRAGMENTOS MÍNIMOS}

Las novelas formadas por series de minificción (textos literarios extremadamente breves) constituyen un género liminal (es decir, fronterizo) desde todos los puntos de vista posibles, pues ahí se exhiben, se ponen en juego y se ironizan diversas fronteras y convenciones genéricas, y muy especialmente la frontera de la extensión mínima que puede requerir un texto para tener suficiente valor literario, así como el concepto de la unidad de sentido sin fisuras que presuponen la novela y el cuento de carácter convencional.

Las series de minificción constituyen un género textual cuya identidad se define precisamente por ubicarse en la incertidumbre, es decir, en el espacio fronterizo, liminal, paradójico, indeterminado, productivo, en el que toda interpretación excluyente es literariamente irrelevante.

Las sorprendentes posibilidades literarias que ofrece la escritura extremadamente breve han sido exploradas de manera sistemática a lo largo del siglo $\mathrm{XX}, \mathrm{y}$ el desarrollo más notable de este género se ha producido en el contexto hispanoamericano.

La lectura de estos textos termina por borrar cualquier lógica jerárquica y definitiva. La lectura crítica de los ciclos de minificción que constituyen una novela plantea problemas fundamentales para la teoría literaria y para la práctica de la escritura, pues son a la vez novela fragmentaria, ciclos cuentísticos y series de minificción. De manera implícita se plantean las preguntas genéticas originarias: ¿son novelas? ¿son cuentos? ¿son literatura? La respuesta a éstas y otras preguntas depende del marco desde el cual se formula cada una de ellas, y esa ambigüedad proteica es lo que define la naturaleza genérica, estructural y semántica de la minificción serial.

En síntesis, las minificciones integradas son literariamente fronterizas en varios sentidos. En primer lugar, son textos genéricamente fronterizos en su interior, pues cada uno suele incorporar simultánea o alternativamente elementos de narrativa, poesía o ensayo. Al incorporar elementos de diversos géneros literarios, cada uno de estos textos se encuentra en la frontera entre narración y ensayo, entre narración y poesía o entre ensayo y poesía. 
Por otra parte, los textos de minificción también tienen una naturaleza genéricamente fronteriza al parodiar o incorporar en su interior elementos de diversos géneros extraliterarios (como viñeta urbana, crónica de viaje, escritura epistolar, manual de instrucciones, descripción taxonómica y virtualmente cualquier otra forma posible de escritura). Al incorporar elementos de diversos géneros extraliterarios, cada uno de estos textos se encuentra en la frontera entre la escritura tradicionalmente considerada como literaria y la que tradicionalmente es considerada como ajena a la literatura ${ }^{5}$.

Todas estas formas de itinerancia o hibridación genérica son posibles gracias a la presencia de estrategias irónicas. En estos textos la presencia de la ironía (generalmente en forma de parodia, sobreentendido o juegos de lenguaje) funciona como una especie de ácido retórico que disuelve las fronteras entre géneros literarios, y entre la escritura literaria y la no literaria.

Por último, la minificción también és fronteriza al estar en permanente itinerancia entre las formas de escritura moderna (caracterizada por estrategias de ironía estable) y las formas de escritura posmoderna (caracterizada por estrategias de ironía inestable) ${ }^{6}$.

En las series y ciclos textuales de minificción de autores hispanoamericanos y chicanos se encuentra una itinerancia entre las fronteras señaladas, es decir, entre narración, poesía y ensayo; géneros literarios y extraliterarios; pretextualidad y architextualidad; ironía estable e inestable. Pero al tratarse de series formadas por textos de extensión mínima, en estos casos es necesario retomar la discusión acerca de la definición de fronteras entre el todo y la parte, es decir, entre la pertenencia simultánea de cada texto a una unidad serial más compleja (una novela) o a un ciclo narrativo específico (un cuento) sin por ello perder su autonomía como unidad textual (una minificción).

Esto último significa que, además de las fronteras señaladas anteriormente, las minificciones también son genéricamente fronterizas cuando forman parte de una serie, pues cada texto ofrece al lector la posibilidad de ser leído de manera autónoma o como parte de una unidad serial. Por lo tanto, los ciclos narrativos de minificción pueden ser leídos, alternativamente, como novelas de fragmentación extrema (novelas formadas por frag-

\footnotetext{
${ }^{5}$ La naturaleza híbrida de la minificción ya ha sido señalada por numerosos investigadores. Cf. A. Berchenko, 1997 y otros. Por ejemplo, Violeta Rojo afirma: «(...) aunque los minicuentos tienen algunas características de los cuentos tradicionales y siguen perfectamente loa rasgos diferenciales del género, también tienen otro tipo de características. Así, entre los minicuentos podemos encontrar desde fábulas hasta ensayos, pasando por todas las variaciones posibles de las formas simples y de los escritos no literarios. Es por esta razón que se habla del carácter proteico de los minicuentos, ya que su forma, como la de Proteo, es cambiante» (V. Rojo 1997, 93).

${ }^{6} \mathrm{La}$ distinción entre ironía estable e inestable proviene de Wayne Booth en su Retórica de la ironía. Madrid, Taurus, 1986 (1974)
} 
mentos muy breves) o como series de minicuentos integrados (ciclos de cuentos muy breves que constituyen una novela).

Los antecedentes canónicos de las minificciones integradas en la literatura mexicana son Cartucho (1920) de Nellie Campobello y La feria (1963) de Juan José Arreola, y muchas de las novelas más recientes que forman parte de esta tradición genérica tienden a ser metaficcionales ${ }^{7}$. En el resto de Hispanoamérica hay notables ejemplos de novelas formadas por minificciones, muchas de ellas elaboradas con una notable carga intertextual ${ }^{8}$.

Este género aún está en espera de ser estudiado atendiendo a su naturaleza genérica, y reconociendo que se trata de una escritura que se distingue de los cuentos integrados, la novela fragmentaria y las otras series de minificción.

\section{CICLOS DE MINIFICCIÓN: LAS SERIES DE VARIA INVENCIÓN}

Los ciclos de minificción son series que, sin tener la extensión ni la estructura de una novela, están formadas por parodias y pastiches genéricos, así como por diversos juegos estructurales, intertextuales y lingüísticos.

En Hispanoamérica hay una riquísima tradición de ciclos textuales de minificción, con antecedentes tan distinguidos como De fusilamientos (México, 1940) de Julio Torri, y El hacedor (Argentina, 1960) de Jorge Luis Borges. En este género es posible distinguir entre ciclos de ciclos (con la extensión de un volumen autónomo) y ciclos breves, que no alcanzan la extensión de un volumen y generalmente forman parte de un material con mayor extensión.

\footnotetext{
${ }^{7}$ Éste es el caso de Los juegos (1967) de René AviLÉs FABILA, ¿ABCDErio o AbeCeDamo? (1975) de Daniel LEYVA, Fantasmas aztecas (1979), Muchacho en llamas (1987) y A la salud de la serpiente (1988) de Gustavo SAINZ; Héroes convocados (1982) de Paco Ignacio TAIBo II, y Cuadernos de Gofa (1981) de Hugo Hiriart. Durante la última década del siglo se intensificó la escritura de este género con una marcada tendencia a la autorreferencialidad, como puede observarse en el caso de La luna siempre será un amor difícil (1994) y Estrella de la calle sexta (2000) de Luis Humberto Crosthwaite; La señora Rodríguez y otros mundos (1990) de Martha CERDA, y Remedios infalibles contra el hipo (1998) de José Ramón RUISÁNCHEZ.

${ }^{8}$ La guaracha del Macho Camacho (1976) y La importancia de llamarse Daniel Santos (Puerto Rico, 1989) de Luis Rafael SÁNCHEZ están escritas en forma de crónica musical; Luisa en el país de la realidad (México, 1994) de la salvadoreña-nicaragüense Claribel Alegría está elaborada como crónica poética; Pero sigo siendo el rey (Colombia, 1983) de David Sánchez Juliao es un homenaje textual a la música ranchera mexicana; Tierra de Nadia (Ecuador, 2000) de Marcelo Báez está escrito como un diario en internet. Y las novelas chicanas Klail City (1976) de Rolando HiNOJOSA y La casa en Mango Street de Sandra Cisneros (esta última traducida al español por Elena Poniatowska en 1995) son relatos autobiográficos y a la vez retratos de una comunidad lingüística y cultural.
} 
Entre los ciclos de ciclos en Hispanoamérica destacan títulos como Varia invención (1949) y Palíndroma (México, 1971) de Juan José Arreola, y muchos otros ${ }^{9}$. En el interior de cada uno de estos títulos hay una notable diversidad de temas, tonos y géneros, y sin embargo en todos ellos se logra una notable unidad literaria debida a la evidente voluntad de estilo de sus autores.

Los ciclos breves tienen como referente obligado la serie de minificciones contenidas en la sección Material plástico incluida en el volumen de Historias de cronopios y de famas (Argentina, 1974) de Julio Cortázar. En esta clase de minificciones de naturaleza proteica encontramos juegos genéricos a la manera de pastiches, como la serie de Cosas que se encuentra en Disertación sobre las telarañas (1980) o en la serie de Rarezas incluida en Discutibles fantasmas (México, 2001) de Hugo Hiriart.

Los ciclos de minificción suelen adoptar una estructura lúdica, y con frecuencia tienen una naturaleza abiertamente intertextual, como Falsificaciones (Argentina, 1966) de Marco Denevi; La oveja negra y demás fábulas (México, 1969) de Augusto Monterroso; Caja de herramientas (México, 1989) de Fabio Morábito, y Adivinanzas (México, 1989) del peruano Manuel Mejía Valera. En estos casos se ponen en juego las reglas genéricas de diversas tradiciones extraliterarias, como mitos, fábulas, alegorías, catálogos y juegos infantiles.

Otros ciclos de minificción están estructurados alrededor de diversos juegos lingüísticos. Éste es el caso de Exorcismos de esti(l)o (1976) de Guillermo Cabrera Infante, donde se proponen reglas diversas para cada breve ciclo de textos ${ }^{10}$. Una variante frecuente de ciclos de minificción en Hispanoamérica es la colección de viñetas y crónicas brevísimas ${ }^{11}$.

\footnotetext{
${ }^{9}$ Mencionemos las series humorísticas de Me río del mundo (Venezuela, 1984) de Luis BRITTO GARCía; Despistes (Uruguay, 1989) de Mario BenedeTti; La Musa y el Garabato (México, 1992) de Felipe GARRIDO; Textos extraños (1981) y Cuaderno imaginario (México, 1990) de Guillermo SAMPERIO; La felicidad y otras complicaciones (México, 1988) del chileno Hernán LAVÍn CERDA; La sueñera (1984), Casa de geishas (1992) y Botánica del caos (Argentina, 2000) de Ana María SHUA, y Retazos (México, 1995) de Mónica LAVín.

${ }_{10}$ Otros casos notables son Léérere (México, 1986) de Dante Medina, donde se descoyuntan las reglas sintácticas con efectos humorísticos, y Sea breve (Guatemala, 1999) de Otto-Raúl González, donde también hay numerosos juegos de lenguaje. Un caso extremo de juego estructural es el propuesto en Infundios ejemplares (México, 1969) de Sergio Golwarz, donde cada texto es más breve que el anterior, produciendo así lo que el autor llama una estructura infundibuliforme, es decir, en forma de embudo.

${ }^{11}$ En México se pueden encontrar ejemplos como Gente de la ciudad (México, 1986) de Guillermo Samperio; Ciudad por entregas (México, 1996) de Norberto de la Torre, y Crónicas romanas (México, 1997) de Ignacio Trejo Fuentes. Una variante de esta modalidad son las series de crónicas periodísticas extremadamente breves, como Patas arriba (Uruguay, 1998) de Eduardo Galeano y la serie de crónicas de viaje igualmente sintéticas en Objetos reconstruidos (Argentina, 1979) de Noé Jitrik.
} 


\section{UN CASO ESPECIAL: LOS BESTIARIOS FANTÁSTICOS}

El estudio de los bestiarios, como una forma especial de ciclos de minificción, requiere un tratamiento por separado, pues su especificidad genérica en la tradición hipanoamericana es de naturaleza opuesta a la tradición europea.

En efecto: en la milenaria tradición europea se bestializan los rasgos humanos en un proceso de degradación moral que ha producido vampiros, gárgolas, duendes, homúnculos y hombres-lobo. En cambio, la tradición hispanoamericana de los bestiarios surgió cuando los informantes de los cronistas de Indias (entre ellos, Gonzalo Fernández de Oviedo y muchos otros) describían la fauna y la flora del Nuevo Mundo con una mirada asombrada, proyectando rasgos humanos sobre los fenómenos naturales.

Es así como encontramos dos grandes tendencias en la tradición de los bestiarios hispanoamericanos, ambas de carácter antropomórfica. La primera de ellas hunde sus raíces en las tradiciones precolombinas, especialmente mesoamericanas, y produce bestias sagradas y ominosas, debido a su íntima proximidad con la muerte. Esta tradición fue incorporando poco a poco, a lo largo de la Colonia, una rica iconografía apocalíptica y extemporáneamente milenarista, revitalizada en los últimos años del siglo XX por la generación de los narradores más jóvenes.

La otra tradición es más moderna y se ha desarrollado especialmente a partir de la década de 1950, produciendo bestias alegóricas, a veces paródicas, en ocasiones hiperbólicas o incluso descritas en un estilo poético. En esta tradición los bestiarios llegan a emplear el sentido del humor y la ironía al señalar la naturaleza paradójica de seres que, sin ser completamente humanos, exhiben a la manera de fábulas sin moraleja las contradicciones de la condición humana.

Mencionemos una docena de los bestiarios imprescindibles en la tradición hispanoamericana publicados durante la segunda mitad del siglo XX para ilustrar la existencia de ambas tradiciones. Los principales textos de la zoología fantástica se inician precisamente con el Manual de zoología fantástica de Jorge Luis Borges y Margarita Guerrero (Argentina, 1954). Pocos años después Juan José Arreola escribe su Bestiario, que es una de las cumbres de poema en prosa escrito en nuestra lengua (México, 1959). Y en la tradición propiamente poética se inscribe el Álbum de zoología de José Emilio Pacheco (México, 1985). También en México se publicó la serie cuentística del Bestiario doméstico de Brianda Domecq, aunque éste no está formado por minificciones.

En la provincia mexicana se han hecho algunas aportaciones interesantes a la tradición de los bestiarios de minificciones, como El recinto de animalia de Rafael Junquera (Xalapa, 1999), mientras en Toluca se publi- 
có un apócrifo Bestiario de Indias (acompañado poco después por un Herbario de Indias) firmados por el Muy Reverendo Fray Rodrigo de Macuspana, que es el seudónimo utilizado por su recopilador, el investigador universitario Marco Antonio de Urdapilleta (UAEM, 1995). Y en Guadalajara, el investigador Raúl Aceves escribió un Diccionario de bestias mágicas y seres sobrenaturales de América (Universidad de Guadalajara, 1995).

En cuanto a la tradición de las parábolas irónicas, en 1951 se publica el conocido Bestiario de Julio Cortázar, si bien ya está más emparentado con el Bestiario de Franz Kafka que con las Crónicas de Indias, y está formado por cuentos de extensión convencional. En 1969 se publica $L a$ oveja negra y demás fábulas de Augusto Monterroso (nacido en Honduras, de nacionalidad guatemalteco y radicado en México). Y en Chile se publica el Bestiario urbano de Ricardo Cantalapiedra (FCE, 1989).

En México contamos también con escritores en esta tradición, empezando con René Avilés Fabila, conocido por sus minicrónicas de la estupidez humana en sus alegorías de Los animales prodigiosos (1989). Poco después, el poblano Pedro Ángel Palou publica sus parodias tiernas y sarcásticas en Amores enormes (1991). Y en 1999, Ediciones El Ermitaño publicó dos colecciones simultáneas: los minipoemas del Bichario (1999) del uruguayo Saúl Ibargoyen, avecindado en México desde hace muchos años, y un volumen colectivo con el título Bestiario fantástico, surgido del taller de escritura de Bernardo Ruiz, en el cual se incorporan minificciones inscritas en todas las tradiciones señaladas en este breve recuento, desde el tono ominoso y apocalíptico hasta las alegorías irónicas de una cotidianidad paradójica.

En términos generales, los textos de la tradición apocalíptica o fabulística adoptan un tono hierático, a veces poético, casi urgente, en ocasiones oracular, como el presagio de algo irrevocable y definitivo. Y por su parte, los textos de la tradición irónica son cuentos fantásticos escritos como alegorías de la lectura, del transcurso del tiempo o de las debilidades humanas. En estos cuentos el narrador se apropia de una situación cotidiana para transformarla en una bola de cristal donde se puede observar, como en un aleph, cualquier otra situación igualmente cotidiana (la del lector). Estos textos son espejos anamórficos que devuelven a sus lectores una imagen a la vez extraña y familiar. En ellos parece responderse a la pregunta por la identidad de los personajes, señalando nuestra condición animal, a la vez finita y compleja.

\section{CUENTOS DISPERSOS: EN ESPERA DE UNA RELECTURA}

Otra estrategia de articulación entre el todo y las partes consiste en la existencia de capítulos de novela con la suficiente autonomía para ser con- 
siderados como cuentos. En este caso estamos ante los cuentos dispersos en diversas novelas (como los de Fernando del Paso) ${ }^{12}$ o los cuentos intercalados en una misma novela ${ }^{13}$.

Un caso similar al anterior puede ser producido durante el acto de la lectura. Se trata del producto de un lector especializado que establece afinidades formales o genéricas entre textos de un mismo autor o de autores distintos, y reúne estos textos para así poner en evidencia esta propuesta de lectura. Se trata de la compilación de cuentos, minificciones, capítulos o fragmentos de uno o varios textos que son reorganizados para producir proyectos editoriales específicos.

Aquí encontramos las antologías con una estructura capitular propia o las elaboradas por Jorge Luis Borges y Adolfo Bioy Casares (Cuentos breves y extraordinarios, 1953) y más tarde por Edmundo Valadés (El libro de la imaginación, 1976), quienes seleccionaron fragmentos extremadamente breves de obras muy voluminosas, creando así numerosas minificciones a partir de un acto nominal y de lectura. Otro caso de cuentos dispersos consiste en la publicación de los cuentos completos de un autor canónico, como las series anotadas que han sido publicadas durante varias décadas por las colecciones especializadas de Cátedra y de Castalia, y las no menos conocidas colecciones de Aguilar y de Alfaguara. Y también se puede hablar aquí de las distintas compilaciones de cuentos elaboradas por un mismo autor en diversos momentos, como el caso de Sergio Pitol, cuya reorganización editorial de sus propios cuentos alcanza ya numerosas versiones.

Otra variante de este género lo constituyen las recopilaciones de textos breves realizadas por un mismo autor. Así, por ejemplo, en los Cuentos en miniatura (Argentina, 1976) de Enrique Anderson Imbert se han reunidos los casos de este autor dispersos en sus libros anteriores, es decir, los minicuentos fantásticos y lúdicos que él mismo colocaba al final de cada sección de cuentos de extensión convencional. La reunión de textos que en otro contexto podría parecer una escritura ancilar adquiere otorga así una dimensión más relevante a estos materiales, pues al leerlos en esta compilación resultan más evidentes sus elementos comunes, como parte de un proyecto literario muy consistente.

Un tipo particular de cuentos dispersos lo constituyen aquellos que están inscritos en una tradición genérica (o subgenérica) particular y que pueden ser encontrados en una serie en la que hay también cuentos de otras tradiciones genéricas. Así, por ejemplo, en el Confabulario de Juan José Arreola encontramos varios cuentos de ciencia ficción («El guardagujas», «Anun-

${ }^{12}$ Fernando DEL PASO: Cuentos dispersos. Selección y prólogo de Alejandro Toledo. México, UNAM, Serie Confabuladores, 1999

${ }^{13}$ Un ejemplo español se encuentra en El desorden de tu nombre de Juan José MiLlás. 
cio», «En verdad os digo» y «Baby H. P.») entremezclados con cuentos fantásticos, alegóricos y realistas.

\section{UNA CONCLUSIÓN PARA EMPEZAR: FRAGMENTOS, DETALLES Y FRACTALES}

El punto de partida para la discusión sobre las relaciones estructurales entre la parte y el todo es la distinción entre fragmento (referido a la ruptura de una totalidad en elementos que conservan una relativa autonomía textual) y detalle (referido a la segmentación provisional de una unidad global, íntegra e indivisible). Un tipo particular de detalle es el fractal (referido a todo texto que contiene rasgos genéricos, estilísticos o temáticos que comparte con los otros de la misma serie). Así pues, el fragmento es lo opuesto al fractal, pues el primero es autónomo, mientras el segundo conserva los rasgos de la serie. Pero, mientras el detalle es resultado de una decisión del autor, el fractal es producido por el proceso de lectura. En todos los casos estamos ante el ocaso de la integridad de los géneros tradicionales.

El detalle o fractal es una unidad narrativa que sólo tiene sentido en relación con la serie a la que pertenece ${ }^{14}$. El fragmento es una unidad narrativa que conserva su autonomía literaria o lingüística frente a la totalidad estructural de la novela a la que pertenece ${ }^{15}$.

En todos los casos el estudio de las series textuales requiere reconocer las consecuencias que tiene el uso extremo de la elipsis, los sobreentendidos, la ambigüedad semántica, la catáfora narrativa (el anuncio de una continuación narrativa en otro segmento textual) y la extrema economía de recursos. No es casual que estos elementos son estrategias textuales características de la minificción literaria.

Cada uno de los títulos mencionados hasta aquí puede ser sometido a un análisis en el que sean reconocidas las estrategias de organización estructural de cada serie, con el fin de estudiar las fronteras entre el todo y la parte. A estos mecanismos de unidad y fragmentación se les podría denominar estrategias de serialidad. En resumen, estas estrategias son de carácter hipotáctico (series de unidades narrativas subordinadas, donde cada una está ligada en un orden sintáctico necesario) y paratáctico (series de

\footnotetext{
${ }_{14}$ Éste es el caso de cada una de las secciones de las novelas estructuradas siguiendo una lógica de carácter musical, como La creación (1959) de Agustín YÁÑEZ, ¿Quién desapareció al Comandante Hall? Sinfonía metropolitana para cinco voces (1998) de Julia Rodríguez o Bolero (1997) de Pedro Ángel PALOU. En los primeros, cada capítulo adopta el ritmo de escritura que corresponde al tono de la partitura musical. En el último, cada capítulo adopta el título de un bolero, indicando también su duración.

${ }^{15}$ Éste es el caso del capítulo 62 de Rayuela (que dio lugar a la novela 62 / Modelo para armar) o el ya mencionado capítulo 68 de esa misma novela (que está escrito en un idiolecto específico de ese texto, el glíglico).
} 
unidades narrativas coordinadas, donde cada una es relativamente autónoma y recombinable durante la lectura). Estas estrategias incluyen, entre otras, las de carácter anafórico (cuando una unidad narrativa retoma un hecho anterior), catafórico (al anunciar un hecho por ocurrir), así como elipsis (suprimiendo un hecho que se da por ocurrido), analepsis (también conocida como flashback) y prolepsis (flashforward). Y todas ellas pueden afectar, en distintos momentos del relato, a elementos narrativos fundamentales, como los personajes, el tiempo, el espacio, el género o el estilo.

Por otra parte, con el fin de mostrar cómo se articulan estas relaciones entre unidad y fragmento, en cada serie es posible reconocer la presencia de la ironía (estable e inestable) como mecanismo de disolución de la unidad genérica, así como también los mecanismos de intertextualidad, en particular aquellos ligados a la fusión de varios géneros literarios y a la presencia simultánea de géneros extraliterarios.

La frontera es una noción que permite definir conceptos, establecer límites, legislar exclusiones, dictaminar perímetros, reglamentar identidades, asentar principios, establecer propiedades. Las series de textos breves no sólo exigen una reformulación de las fronteras entre el todo y las partes, y de las fronteras entre diversos géneros canónicos, sino una reformulación de la frontera más importante en el espacio literario: la que existe entre el proceso de creación y el acto de leer.

\section{BIBLIOGRAFÍA}

ANDERSON IMBERT, Enrique: «Cuentos enlazados» en Teoría y práctica del cuento. Barcelona, Ariel, 1992, 115-119.

BERCHENKO, Adriana: «Proposiciones para una estética del cuento brevísimo: ¿un género híbrido?» en América, vol. 18, tomo 1: Formes breves de l'expression culturelle en Amérique Latine de 1850 a nous jours. Poétique de la forme breve. Conte, Nouvelle. París, CRICCAL (Centre de Recherches Interuniversitarire sur les Champs Culturelles en Amérique Latine), Presses de la Sorbonne Nouvelle, 1997, 25-44.

BLANC, Jean-Nöel: «Pour une petite histoire du 'roman-par-nouvelles' et de ses malentedus» en Le genre de la nouvelle dans le monde francophone au tournant du XXIe siecle. Actes du colloque de l'Année Nouvelle a Louvain-la-Neuve, 26-28 avril 1994. Sous la direction de Vincent Engel. Québec, L'instant meme, 1995, 173-178.

BORGES, Jorge Luis: «Un nuevo género literario» en Entrevistas de Georges Charbonnier con Jorge Luis Borges. México, $4^{\mathrm{a}}$ ed. en español, 2000 (1967), 78-89.

BRIGGS, John \& F. David PEAT: «La estética de los fractales» en Las siete leyes del caos. Las ventajas de una vida caótica. Barcelona, Grijalbo, 1999, 152-154.

CAlabrese, Omar: «Detalle y fragmento» en La era neobarroca. Madrid, Cátedra, 1989 (1987), 84-105.

Cluff, Russell: «Los Ferri: la saga familiar de Sergio Pitol» en El cuento mexicano. Homenaje a Luis Leal. Ed. Sara Pott Herrera, México, UNAM, 1996, 379-406.

-: «Doce peregrinajes maravillosos» en Si cuento lejos de ti. La ficción en México. Tlaxcala, UAT, 1998, 61-79. 
-: «Colonizadores y colonizados en Zitilchén: la secuencia de cuentos de Hernán Lara Zavala» en Revista de Literatura Mexicana Contemporánea, núm. 3, 1996, University of Texas at El Paso (UTEP), 56-66.

CORRAL, Will: «Las posibilidades genéricas y narrativas del fragmento: formas breves, historia literaria y campo cultural hispanoamericanos» en Nueva Revista de Filología Hispánica, El Colegio de México, 44:2 (1996), 451-487.

D'Lugo, Carol Clark: The Fragmented Novel in Mexico. The Politics of Form. Austin, The University of Texas Press, 1997.

DunN, Maggie \& Ann MORRIS: The Composite Novel. The Short Story Cycle in Transition. New York, Twayne Publishers, 1995.

EzAMA GIL, Ángeles: «El libro: la colección de cuentos» en El cuento de la prensa y otros cuentos. Aproximación al estudio del relato breve entre 1890 y 1900 . Universidad de Zaragoza (España), 1992, 35-39.

FUENTES, Carlos: «Nuevo tiempo mexicano». Entrevista con Ricardo Cayuela Gally, incluida en Carlos Fuentes: territorios del tiempo. Antología de entrevistas. Compilación e introducción de Jorge Hernández. México, FCE, 1999, 253-265.

GlaNTZ, Margo: «Juan José Arreola y los bestiarios» en Latin American Fiction Today. A Symposium. Ed. Rose S. Minc. Takoma Park, Maryland, Hispamérica, 1980, 61-70.

GuTIÉRREZ, Domingo: Claves para la lectura de La colmena de Camilo José Cela. México, Daimón, 1986.

HAYLES, Katherine L.: «Chaos and Culture» en Chaos Bound. Orderly Disorder in Contemporary Literature and Science. Traducción al español como La evolución del caos. Barcelona, Gedisa, 1998 (1990), 214-222.

HELDRICH, Philip: «Connecting Surfaces: Gertrude Stein's Three Lives, Cubism, and the Metonimy of the Short Story Cycle» en Studies in Short Fiction, Newberry College, South Carolina, 34:4, Fall 1997, 427-439.

INGRAM, Forrest L.: Representative Short Story Cycles of the Twentieth Century. Studies in a Literary Genre. La Haya / París, Mouton, 1971.

KENNEDY, Gerald, ed.: Modern American Short Story Sequences. Composite Fictions and Fictive Communities. Cambridge University Press, 1985.

LANDOW, George P.: Hipertexto. La convergencia de la teoría crítica contemporánea y la tecnología. Barcelona, Paidós, 1995 (1992).

LUSCHER, Robert M.: «Short Story Sequence: An Open Book» en Short Story Cycle at a Crossroads. Ed. Susan Lohafer \& Jo Ellyn Clarey. Louisiana State University, 1989, 148-167.

LYNCH, Gerald: «The One and the Many: Canadian Short Story Cycles» en The Tales We Tell. Perspectives on the Short Story. Ed. Barbara Lounsberry et al. Westport, Connecticut / Londres, Greenwood Press, 1998, 35-45.

MARTÍNEZ FERNÁNDEZ, José Enrique: El fragmentarismo poético contemporáneo. Universidad de León (España), 1996.

MURRAY, Janet H.: Hamlet en la holocubierta. El futuro de la narrativa en el ciberespacio. Barcelona, Paidós, 1999 (1997).

REID, Ian: «Brevity Expanded: Cycle» en The Short Story. Londres, Methuen, 1977, 46-49.

RODRÍGUEZ, Jaime Alejandro: Hipertexto y literatura. Una batalla por el signo en tiempos posmodernos. Bogotá, Pontificia Universidad Javeriana, 1999.

RoJO, Violeta: «Características del mincuento» en Breve manual para reconocer minicuentos. México, UAM Azcapotzalco, 1997, 55-116.

SCHOLZ, L.: «Fragmentarismo en Klail City de Rolando Hinojosa» en Ensayos sobre la modernidad literaria hispanoamericana, Universidad de Murcia (España), 2000, 107-114.

VoUILlamoz, Núria: Literatura e hipermedia. La irrupción de la literatura interactiva: precedentes y crítica. Barcelona, Paidós, 2000. 


\section{RESUMEN}

Fragmentos, fractales y fronteras: Género y lectura en las series de narrativa breve, por Lauro Zavala.

En este trabajo señalo la existencia de varias estrategias de escritura, edición y lectura de series narrativas que permiten relativizar las fronteras convencionales entre la unidad textual (en particular, la unidad de la novela) y la diversidad genérica (en particular, la identidad de cada cuento o minificción). Estas estrategias son las que permiten reconocer las diferencias entre cuentos integrados, novela fragmentaria, minificciones integradas, ciclos de minificción y cuentos dispersos. Lo que está en juego en el estudio de las series de textos breves es el reconocimiento de las posibilidades de lectura que ofrecen las manifestaciones textuales de lo mismo y lo múltiple, en la reformulación de las fronteras entre el todo y las partes.

Palabras clave: Cuentos integrados, novela fragmentaria, ciclos narrativos, minificción, bestiarios, lectura como producción.

\section{ABSTRACT}

In this paper I study some strategies for reading narrative series that enable the reader to play with the conventional boundaries between textual unity (in particular, that of the novel) and generic diversity (in particular, that of the short and the short-short story). These strategies enable the reader to distinguish between short story cycles, short-short story cycles, fragmentary novel, and dispersed stories. What is at stake is a new aesthetics of reading which produces a re-statement of the very boundaries between the whole and its parts.

Key words: Short story cycles, fragmentary novel, short-short story, minifiction, bestiaries, reading as production. 